\title{
ERRATUM
}

\section{Erratum to: Authors' response: Origin of the 24-h rest arm}

Franco Laghi', Nausica D'Alfonso and Martin J. Tobin

(C) 2016 Springer-Verlag Berlin Heidelberg and ESICM

\section{Erratum to: Intensive Care Med (2014) 40:1609-1610 DOI 10.1007/s00134-014-3448-8}

This reply cited neither the letter to which it responded [1] nor the article that formed the subject of the correspondence [2]. The authors are pleased to rectify this shortcoming here.

1. Esteban A, Benito S, Frutos-Vivar F (2014) Sometimes, 20 years are many.... Intensive Care Med 40(10):16071608. doi:10.1007/s00134-014-3430-5

2. Laghi F, D’Alfonso N, Tobin MJ (2014) A paper on the pace of recovery from diaphragmatic fatigue and its unexpected dividends. Intensive Care Med 40:12201226. doi:10.1007/s00134-014-3340-6

Published online: 31 March 2016

The online version of the original article can be found under doi:10.1007/s00134-014-3448-8.

*Correspondence: flaghi@lumc.edu

Division of Pulmonary and Critical Care Medicine, Edward Hines Jr.

Veterans Affairs Hospital (111N) and Loyola University of Chicago Stritch

School of Medicine, Hines, IL 60141, USA

\section{Springer}

